\title{
Facing "change" in the process of designing and developing web-based learning environments
}

\section{S. Karunanayaka*}

Department of Secondary and Tertiary Education, the Open University of Sri Lanka

The integration of information and communication technologies (ICTs) into education has provided opportunities for changes in teaching and learning by allowing greater flexibility, interactivity and accessibility. Hence, integration of ICTs into education demands acquisition of new competencies as well as changes in pedagogical beliefs.

A case study was conducted to investigate the process of design and development of Internet-based study materials by a group of teacher educators, who were familiar with using, designing and developing textbased study materials, yet novices to web designing. Throughout this process, data were collected using multiple techniques such as observation of Web Study guides (WSGs), conducting in-depth interviews and obtaining reflective reports. This paper focuses on how these teacher educators faced 'change', in the process of designing and developing webbased learning environments, as novice web-designers.

The WSG development process was found to be a gradual adaptation to a new instructional mode by the participants, influenced by many factors such as previous instructional experiences, prior exposure to technology, skill levels, immersion in technology, time constraints, assessment focus and cultural practices, that in turn affected their 'change' of concepts and understandings in the design process. The process indicated a change over time with respect to participants' skill development, attitude towards technology, instructional approaches and pedagogical beliefs. In a majority, more emphasis was placed on skill development over pedagogical content knowledge and design processes, indicating the difficulty of shifting from traditional instructivist approaches towards a more constructivist approach. However, the future expectations expressed by the participants indicated their conceptual changes that had occurred during this process. If educators are to be 'agents of educational change', they need not only the technology to enhance their practices, but also the support and the time for them to adapt to technology. 


\section{Introduction}

Teaching and learning are in a process of a paradigm shift, from a prescriptive, didactic approach to a more flexible and an individualized learning situation where active, constructive learning is encouraged (Davis et al., 1997). The integration of information and communication technologies (ICTs) into education has provided opportunities for such changes in teaching and learning by allowing greater flexibility, interactivity and accessibility (Visser \& Jain, 1997).

Collis (1998a) indicates this significant influence of Information Technology (IT) in educational change in arguing that:

New information technologies and particularly the Internet, in dramatically transforming access to information, are changing the learning and research process, how we search, discover, teach and learn (Langlois, 1997 cited by Collis, 1998a, pp. 373-374).

Thus, new ICTs can have a significant influence on changing teaching and learning approaches, mainly because they are not just passive methods of delivering information, but are interactive strategies that allow learners to manipulate and control information. Hence, the integration of ICTs into education demands the acquisition of new competencies as well as changes in pedagogical beliefs. This paper focuses on how a group of teacher educators faced 'change', in the process of designing and developing web-based learning environments, as novice web-designers.

\section{Review of Literature}

\section{Change efforts in adopting innovations}

In contrast to the rapid changes in evolving new technologies, the associated changes in actual teaching and learning situations are occurring rather slowly. Literature reveals that the impact of IT in changing the people, the way they think and act, is not so significant (Albright, 1996, Collis, 1998a, Collis, 1998b, Underwood, 1997).

Despite the rapidity of technological advancements and their influences upon teaching and learning, the actual adoption of them by people is not so rapid.

Observing that change efforts often focus on materials overlooking people, Fullan and Stiegelbauer (1991) argue that educational innovation requires not only a change of teaching resources, but also of 
teaching strategies and beliefs. Fullan (1993) claims that, if the intended outcomes from an innovation are to be achieved, changes in actual practices along all these three dimensions, as indicated below, are essential.

1. the possible use of new or revised materials (direct instructional resources such as curriculum materials or technologies),

2. the possible use of new teaching approaches (new teaching strategies or activities) and,

3. the possible alteration of beliefs (eg. pedagogical assumptions and theories underlying particular new policies or programmes) (Fullan, 1993, pp.37).

The integration of modern computer technologies into education is such an innovation. These technologies offer the potential and opportunities for teachers to change along the above dimensions which will enhance their professional endeavours. Yet they face difficulties in keeping pace with the rapidity in the development of information technologies and their applications to education.

\section{The change process}

Change is a process that takes place over time. The introduction of new innovations to teaching and learning requires a change in teachers' and learners' thinking and beliefs. Yet how each person moves through this change process is unique to each individual.

The 'Diffusion of Innovations Model' by Rogers (1995) is a model of change that explains the change processes in the adoption of an innovation. It describes how innovations are adopted by groups of people. People fall into a continuum of categories based on their use of an innovation. Innovators are the first to experiment with the new products which activate the diffusion process. This would be only $2.5 \%$ of the whole group. Next, at the 'early adopters' stage, the innovation will be utilised, by $13.5 \%$. This will lead to acceptance of the innovation by the 'early majority' group, which comprises $34 \%$ of the total. The 'late majority group', also 34\%, often makes a decision due to peer pressure. The 'laggards' who make up $16 \%$ of the total group, will take much more time to accept the innovation, as they are 'traditionalists'. Further, 'change agents' and 'opinion leaders' also facilitate the adoption process. (Jennings \& Dirksen, 1997). 
The above model provides useful insights into understanding change processes associated with an innovation, and in incorporating procedures to facilitate change to promote acceptance and adoption by teachers. However, as Collis (1998a) claims, 'there is a gap between vision and execution' due to various barriers confronting change. These may be first-order barriers such as technological problems associated with hardware and software, lack of access, time and support to use computers, or second-order barriers such as an unwillingness to change from established classroom practices and beliefs about teaching and computers (Collis, 1996; Ertmer, 1999).

\section{Resistance to change}

Many authors agree that changing the conventional instructional approaches used by teachers is a difficult task. Experienced teachers enjoy stability and their attitudes towards changing established practices are not very positive. Hence, a 'resistance to change' is observed within the teaching profession (Kennewell, 1997, Robinson, 1997, Underwood, 1997;).

It can be argued that unlike other innovations such as audio and video teaching materials, computer technologies will be a difficult innovation for teachers to adopt and accommodate into their practices due to the complexity of these technologies and the lack of teachers' exposure to them.

Underwood (1997) observes that teachers' practices become more stable over lengthy periods of time and maintaining the status quo becomes the norm, resulting in this resistance. Research indicates that many experienced teachers tend merely to assimilate ICTs into their existing instructional approaches (Barrowy \& Lasrena, 1997, Bigum, 1998; Kennewell, 1997;).

The need 'to maintain their professional status with students and colleagues' and the need 'to demonstrate newly acquired computer skills publicly before they have sufficient time to consolidate them' are two main features that distinguish teachers from other computer users (Somekh \& Davis, 1997, pp. 138). These challenges often cause teachers to transfer their conventional teaching practices into IT use.

This indicates the crucial need for more time for teachers to change in all three of the dimensions described by Fullan (1993) - using new materials, using new approaches and altering beliefs - for a real change to occur in the adoption of these technological innovations. Yet, in 
actual situations, teachers are often expected to adopt these technologies within very short time periods. This would undoubtedly result only in superficial changes, such as substituting conventional approaches into technology use as noted before.

Fullan (1993, pp.3) describes this complex situation as follows:

On the one hand, we have the constant and ever expanding presence of educational innovation and reform. On the other hand however, we have an educational system which is fundamentally conservative. The way that teachers are trained, the way that schools are organised, the way that the educational hierarchy operates, and the way that education is treated by political decision-makers results in a system that is more likely to retain the status quo than to change. When change is attempted under such circumstances, it results in defensiveness, superficiality or at best short-lived pockets of success.

The different approaches taken by teachers in using computers in their teaching have been identified as follows: the computer as a 'tutor' that replaces the teacher, as a 'neutral tool' that is mainly useful as a presentation tool, and as a 'cognitive tool' that sets new types of learning tasks for the pupils (Somekh, 1997, pp. 122-123). Only the last approach requires a change in the pedagogy of teachers. In most instances the first two approaches were observed to be the ones commonly used. This indicates a lack of concern in teachers about changing their pedagogy when using IT in education.

\section{Changing design processes}

In the process of designing instruction and instructional materials, the designers will be influenced by many factors that in turn will affect their 'change' of concepts and the understanding of design processes. For instance, the effect of prior experiences and concepts will be a major influence, especially for experienced educators.

On the other hand, designing instruction for a new technological environment such as the WWW poses specific problems, as it requires a different set of skills and understanding. The effect of these factors on designers will consequently have an effect on their products.

When Web-based teaching and learning is integrated into educational institutions, the instructors need to design and structure instructional materials specifically for this novel environment. Johnson (1997) 
claims that instructors often face difficulties in the transition from presenting traditional text-based materials to structuring Web-based materials. Being content experts yet novices as Web designers, the instructors face 'the dilemma of selecting material for a medium of which they have little knowledge' (Johnson, 1997, pp.1258). As a result of this, the instructors may be slow in adapting to this new approach.

Describing an experiment conducted at Aberdeen University, in which the Web replaced face-to-face lectures, Wards and Newlands (1998) observed that preparation of Web materials for a course was very time consuming. They contend that:

The transition from traditional to a computer-based system will involve a considerable investment of time by lecturers new to the Web, in the acquisition of new skills and the preparation of materials

(Wards \& Newlands, 1998, pp.183).

Hence as they claim, although the Web has the potential to enhance teaching and learning, 'there are few shortcuts to the realisation of this potential' (Ward \& Newlands, 1998, pp.182). The educators who design, develop and deliver instructional courses face a challenge in meeting the requirements of the new Web-based learning environment.

Instructional design becomes very important in developing Web-based teaching and learning materials. With the changing paradigms in approaches to teaching and learning from instructivist to constructivist, designers of Web-based materials face a challenge. Not only the experience with this novel technology, but also the multiple avenues exposed by it, place the educators in a complex situation when developing instructional materials for the Web. They face many changes in order to effectively utilise the Web's features to produce a meaningful learning environment. Studying such design processes that teachers use should provide insights into strategies that may facilitate this change.

\section{The study}

A study was conducted at the University of Wollongong, Australia, with the aim of investigating the process of design and development of Internet-based study materials by a group of Sri Lankan teacher educators who were novice Web-designers. This paper focuses on identifying any changes that occurred in the skill development, attitudes towards technology, instructional approaches and pedagogical beliefs of the participants during this process. 
The participants were twelve instructors from different teacher education institutions in Sri Lanka who were familiar with using, designing and developing text-based study materials. At the University of Wollongong, they were enrolled in a one-year study programme leading to the Degree of Master of Education. During this course of study, they had to design and develop a Web Study Guide (WSG), as one of their subject assignments. The participants were experienced teacher educators consisting of four females and eight males, in the age range of 30 - 50 years. Most of them had more than ten years of teaching experience and a majority, more than twenty years in the teaching profession, as teachers and teacher educators. All were professionally qualified graduates, and six had Masters degrees.

The process started with a planning stage during which the participants identified a target group and a topic, found information and organised it, and developed skills in using the software and hardware to produce a WSG. Next, the participants developed the WSGs. The results revealed that, during this process, they were concerned about many aspects, were influenced by a variety of factors, faced a number of issues and obtained support from different sources. At the end, they reflected on this whole learning process and on their final products, the developed WSGs.

\section{Findings and Discussion}

During this process, the participants experienced a new instructional approach based on a new pedagogy. They all claimed that a change in their knowledge, skills and attitudes occurred during this process. As novice Web designers, all participants had no prior knowledge or skills in developing a Web-based learning material. A majority of them had not used the Internet before and some had not even used a computer. This situation resulted in most of the participants feeling 'confused', 'de-motivated', 'uncertain' and 'not confident' at the beginning. As the subject progressed, they gained knowledge and skills on how to complete this task, and their confidence levels rose and motivation increased. At the end, once they had completed their WSGs, all were very satisfied. It was very evident from their remarks that gaining 'hands-on' experiences in using the new technology, and the satisfaction of developing their own Web material, had a great impact on them. 
A majority of the participants claimed that acquiring the technological skills to develop a WSG was their main achievement. This indicated that their main emphasis was on the technology rather than on the pedagogy. It was also apparent from the features of many of the WSGs, that a majority had simply used the newly acquired technical skills to produce a study material that reflected only the conventional instructional approach they were familiar with. As such, they had not actually transformed the text-based content into the Web, but transposed the existing content on to the Web, without making any fundamental changes in the structure of the content.

This observation supports the findings of previous studies done on the integration of computer technologies into teaching and learning situations, where it was found that experienced teachers were resistant to change from their conventional practices and simply assimilated the technology into their existing approaches (Barrowy \& Laserna, 1997; Bigum, 1997; Kennewell, 1997; Underwood, 1997). The results also suggest that, during this entire process where the learners became producers of Web-materials, attention of a majority was paid more to the development of the product than on designing the learning experiences in it.

The participants were very motivated in the task of developing a Webbased study material, as it provided them with an opportunity to learn for the first time, how to use the web technology to produce a study material. Yet they were pressured with time, as this was a course assignment, and they also faced many technical issues as novices. As a result, in most cases, there was no 'real change' observed in their instructional approaches, but only a change in using technological skills in presenting the content. This supports the views of Collis (1998b), Scrum (1999) and Underwood (1997) who claim that, if forced, there would only be a 'superficial change' in the instructional approach.

However, the future expectations expressed by the participants indicated that conceptual changes had occurred during this process. All participants' expectations to develop more Web-based study materials in the future, and the intention of making improvements and changes in their future productions, indicated their increased motivation in practicing and applying the new experiences gained. Further, agreeing that WSGs were very effective teaching-learning environments, all participants expressed their willingness to share their knowledge and skills with others, after returning to Sri Lanka. 
However, the changes they would make when re-developing the WSGs indicated different views. While half of the group wanted to change their design and the instructional approach in the future, the other half had no intention of doing so. Many of the participants whose WSGs followed a traditional instructivist approach wanted to change their presentations to include more constructivist features, such as changing the activity types and allowing the learners to explore by themselves, by providing links to many external Web sites. This observation indicated that they have started to think in a new way, and that their theoretical understanding may have shifted towards a more constructivist learning approach.

This being their first opportunity in developing a WSG, it was a new experience to the participants in both aspects: using new technology and designing pedagogy. As many of them were struggling with the technology most of the time during the process, their concern on pedagogy was of a lower priority. However, at the end of the process, some were able to reflect on their design processes and identify what changes they could make to incorporate a more constructivist learning approach.

In contrast, the participants who did not want to change the instructivist approach even in their future productions, believed that this approach was appropriate in their own cultural context, in which the learners would expect this sort of instruction from the teachers. This implies that despite the fact that the participants themselves had undergone a constructivist learning experience, they were still reluctant to change from their conventional approaches. These observations support the views expressed by Bigum (1998), Kennewell (1997) and Underwood (1997) who claim that there are difficulties in changing established practices of experienced teachers.

The participants' suggestions for using WSGs in Sri Lanka, and their design recommendations, also indicated that a majority were concerned in developing simple, straight-forward WSGs that are objective-based, and which sequence the information in a step by step learning approach, in accordance with the conventional instructivist approach. However, all participants were equally concerned about taking an activity-based approach, and providing more external Web resources as well, implying a change in their thinking along more learner-centred lines than teacher-centred. 
On the other hand, the desire of some participants to include more graphics and sounds in their WSGs implied that they were still unable to move beyond the technical skill development stage. Their main concern was on developing their technical skills in order to use the technology even better, but not on developing the pedagogical aspects. They were reflecting on their design processes mainly from a technological point of view.

This study indicated stages similar to the four stages described in the 'U-curve process' by Mevarech (1997). First, the participants had to struggle with the technological problems and 'survive' them to move on to 'exploration' of using the software. Many could not move beyond the preliminary stages and only a few moved towards 'adaptation' and 'conceptual change', agreeing with Mevarech's observations.

The findings of this study can also be explained using the Diffusion of Innovations Model by Rogers (1995) which explains how an innovation is adopted (Jennings \& Dirkson, 1997). According to this model, only $16 \%$ of a group would be innovators and early adopters who are the first to accept an innovation. Only two out of the twelve participants in the group (16.6\%) demonstrated adopting a new instructional approach in their WSGs. Among the others, a majority indicated attempts to include some new features and intentions to change from the traditional approach in future productions. They fall into either the 'early majority' or the 'late majority' categories. A few who did not want to change from their traditional approach even in future, represent the 'laggards' or 'traditionalists' in the model.

This process also resembled the stages of developing expertise as described by Winn and Snyder (1998). This model claims that a novice cannot directly 'jump' to the expert stage, but has to sequentially move through the other stages: advanced beginners and competent. This implies the need to provide more opportunities for participants to gain multiple experiences in order to move towards expertise.

To design and develop a Web-based learning material, the participants required the development of knowledge and skills in three key areas. They are:

1. Pedagogical content knowledge - which is described as teacher knowledge on the integration of subject matter with pedagogy or "methods" and "strategies" of teaching (Tobin, Tippins \& Gallard, 1994); 
2. Basic skills in Web authoring; and

3. Design processes in a Web environment.

The participants, who were experienced teacher educators, were confident in their subject matter content knowledge. They were experienced in using traditional pedagogical approaches for instruction and familiar with design processes for text-based learning materials. However, they were novices in design processes in a Web environment, and also lacked the basic skills for Web authoring.

The subject provided an environment to support the learners in the class (including the participants and other students), in the key areas as follows:

1.Enhancement of pedagogical content knowledge through readings and discussions.

2.Basic skill development in Web authoring through an activity on Web page construction.

3.Development of understanding design processes in a Web environment through designing and structuring the content in a WSG.

The emphasis that instructors and learners place on each of these three key areas varied during different stages of the process. At the initial stage, the subject instructors placed a high degree of emphasis on development of pedagogical content knowledge and basic Web authoring skills, and less emphasis on design processes. This was because learner understanding of design processes in a Web environment was expected to be developed through the experience of constructing a WSG, and the participants had to acquire the basic skills first, in order to achieve that.

The participants, on the other hand, placed a lower emphasis on developing pedagogical content knowledge at the beginning stages, as they were confident in their current subject knowledge, as well as in their current instructional methods and strategies. However, they placed a high emphasis on skill development, as they lacked Web authoring skills. With respect to the design processes, they had a high degree of skills in text-based material design and thus expressed minimal concerns about that. However, as they were novices in 
designing Web-based learning materials, their concerns were more on developing skills in this aspect.

At the concluding stage of the process, the instructors placed more emphasis on design processes and pedagogical content knowledge, and less on skill development. This was because the main aim of this task was to focus on designing and structuring the content to 'deeply engage the learners', using the basic skills developed at the initial stages of the process.

In contrast, a majority of the participants still placed emphasis on skill development over pedagogical content knowledge and design processes, even at the end. The final products showed that, only two out of the twelve participants had shifted from their traditional instructivist approaches towards a more constructivist approach. However, this does not reflect the real impact of the process upon the participants. During the reflection stage (after submission of the WSG) many indicated a shift in the theoretical understanding that could be expected to reflect in their future design attempts.

Thus, the WSG development process was shown here to be one of gradual adaptation to a new instructional mode. It was influenced by many factors such as previous instructional experiences, prior exposure to technology, immersion in technology, time constraints and assessment focus. The study showed that there is a need for repeated experiences so that participants can continuously reflect upon their work and develop new understanding of the pedagogy required for the effective designing of Web-based learning materials.

\section{Conclusions}

This study demonstrated an evolutionary process in the design and development of Web-based learning materials by the participants, during a specific time period. Each individual's design process was found to be a unique experience, influenced by many factors such as previous experiences, skill levels, exposure to technology, assessment concerns and cultural practices. The process also indicated a 'change' over time with respect to participants' skill development, attitude towards technology, instructional approaches and pedagogical beliefs.

At the entry point, all participants started designing their WSGs as traditional text-based presentations that they were accustomed to. However, adoption of new approaches was observed as their experience levels rose through gaining knowledge and skills in using the new 
technology. They also had to overcome many pedagogical, technological and cultural issues during this process. Adaptation to this new experience was indicated in different ways, to different extents, in each individual's design process. Reflections at the end of the process revealed the intended re-design approaches to be taken by participants in the future.

The design patterns in the WSGs indicated that in most cases the 'power' of the hypertext/hypermedia environment of the Web was inadequately utilised to produce a meaningful learning environment. For instance, hypertext links were mainly used to move from page to page to read the sequentially placed information, or to navigate to the activity page which included some questions and then to the feedback page which provided answers to them. These did not represent a 'real interactivity'.

The resemblance of these presentations to conventional teacherdirected instructional material revealed the fact that the theoretical beliefs of most of these educators had not changed from the traditional role of teachers as 'presenters of information' to passive learners. The Web was largely used to create a 'passive' learning environment, despite its potential to enhance 'active' learning (Brooks, 1997).

Although the final products of a majority showed a predominantly instructivist approach, the willingness of many participants to change from their traditional approach to a more constructivist approach in the future indicated that they have started to think in a new way. This is an important indication that this experience may have stimulated a shift in their theoretical understanding. However, the reluctance of a few to change from their instructivist instructional approach even in future attempts indicates the difficulty in changing the firmly held conventional beliefs. Their interest in only including more multimedia features suggests, that they still have not overcome the impact of technology upon them, and expect more opportunities to experiment with that technology.

If educators are to be 'agents of educational change' (Fullan, 1993), they need not only the technology to enhance their practices, but also the support and the time for them to adapt to technology. Only then would they be ready to change their instructional materials, instructional approaches and most importantly their theoretical beliefs, to accept and use new technology in education. 


\section{References}

Albright, M.J. (1996). Instructional technology and higher education: Rewards, rights and responsibilities. Key note address presented at the annual conference of the Southern Regional Faculty and Instructional Development. LA, Consortium. Baton Range. February 1996. Available online at: http:/ / www.public.iastate.edu/ mikealbr/webcv/ papers/srfidc96.html.

Barrowy, B. \& Laserna, C. (1997). The role of the Internet in the adoption of computer modeling as legitimate high school Science. Journal of Science Education and Technology. 6(1), 3-12.

Bigum, C. (1998). Boundaries, barriers and boarders: Teaching Science in a wired world. Australian Science Teachers' Journal. 44(1), 13-23.

Brooks, D.W. (1997). Web teaching: A guide to designing interactive teaching for the world wide web. New York: Plenum Press.

Collis, B. (1996). The Internet as an educational innovation: Lessons from experience with computer implementation. Educational Technology. November-December, 1996, 21-30.

Collis, B. (1998a). New didactics for university instruction: why \& how? Computers \& Education. 31, 373-393.

Collis, B. (1998b). Implementing innovative teaching across the faculty via the WWW. Paper for the conference "SITE 98", March 1998, Washington, DC. Available online at:

http:/ / education2.edte.utwente.nl/teletophomepage.nsf/PapersUKViewf orm?readform.

Davis, N., Desforges, C., Jesse, J., Somekh, B., Taylor, C. \& Vaughan, G. (1997). Can quality in learning be enhanced through the use of IT. In B. Somekh \& N. Davis (Eds.). Using information technology effectively in teaching and learning-Studies in pre-service and in-service teacher education. (pp. 14-27). London \& New York: Routledge.

Etmer, P. A. (1999). Addressing first and second order barriers to change: Strategies for technology integrations. Educational Technology Research \& Development.47 (4). 47-61.

Fullan, M. \& Stiegelbauer, S. (1991). The new meaning of educational change. (2nd Ed). New York: Teachers College Press.

Fullan, M. (1993). Change forces: Probing the depth of educational reform. London: The Falmer Press. 
Jennings, M.M. \& Dirksen, D.J. (1997). Facilitating change: A process for adoption of Web-based instruction. In B.H. Khan (Ed.). Web-based instruction. (pp 111-116). New Jersey: Educational Technology Publications.

Johnson, B.F. (1997). Making the transition from traditional to Web-based course material. In T. Muldner, \& T.C. Reeves (Eds.). Educational multimedia / hypermedia and telecommunications 1997 Vol.II, (pp. 1257 1258). USA:AACE.

Kennewell, S.E. (1997). The integration of information technology into teachers' decision-making. In D. Passey \& B. Samways (Eds.), Information Technology: Supporting change through teacher education. (pp.169-174). London: Chapman \& Hall.

Mevarech, Z.R. (1997). The U-curve process that trainee teachers experience in integrating computers into the curriculum. In D. Passey \& B. Samways (Eds.). Information Technology: Supporting change through teacher education. (pp. 46-51). London: Chapman \& Hall.

Schrum, L. (1999). Technology professional development for teachers. Educational Technology Research \& Development, 47 (4), 83-90.

Somekh, B. (1997). Classroom investigations: exploring and evaluating how IT can support learning. In B. Somekh \& N. Davis (Eds.). Using information technology effectively in teaching and learning-Studies in pre-service and in-service teacher education. (pp. 114-126). London \& New York: Routledge.

Somekh, B. \& Davis, N. (1997). Getting teachers started with IT and transferable skills. In B. Somekh \& N. Davis (Eds.). Using information technology effectively in teaching and learning-Studies in pre-service and in-service teacher education. (pp. 138-149). London \& New York: Routledge.

Tobin, K., Tippins, D.J. \& Gallard, A.J. (1994). Research on instructional strategies for teaching Science. In D.L. Gabel (Ed.). Handbook of research on science teaching and learning. (pp. 45-93). New York: Macmillan

Underwood, J.D.M. (1997). Breaking the cycle of ignorance: Information technology and the professional development of teachers. In D. Passey $\&$ B. Samways (Eds.). Information Technology: Supporting change through teacher education. (pp.155-158). London: Chapman \& Hall. 
Visser, J. \& Jain, M. (1997). Towards building open learning communities:recontextualising teachers and learners. In D. Passey \& B. Samways (Eds.). Information Technology: Supporting change through teacher education. (pp.20-31). London: Chapman \& Hall.

Ward, M. \& Newlands, D. (1998). Use of the Web in undergraduate teaching. Computers \& Education. 31, 171-184.

Winn, W. \& Snyder, D. (1996). Cognitive perspectives in psychology. In D.H. Jonassen (Ed.). Handbook of research for educational communication and technology. (pp. 112-139) New York: Simon \& Schuster Macmillan. 